\title{
The influence of cervical plate fixation with either autologous bone or cage insertion on radiographic and patient-rated outcomes after two-level anterior cervical discectomy and fusion
}

Burkhardt, Jan-Karl ; Mannion, Anne F ; Marbacher, Serge ; Kleinstück, Frank S ; Jeszenszky, Dezsö ; Porchet, François

\begin{abstract}
PURPOSE We aimed to identify technique-related factors influencing radiographic and patientrated outcomes after two-level anterior cervical discectomy with fusion (ACDF) using either cage or autologous bone, with or without anterior plate fixation (APF). METHODS This single center study was nested within the Eurospine Spine Tango data acquisition system. INCLUSION CRITERIA consecutive two-level ACDF patients (2004-2012) presenting with signs of degenerative cervical radiculopathy or myelopathy. Before and 12 month postoperatively, patients completed the multidimensional Core Outcome Measures Index (COMI); at 12 months postoperatively they also rated the global treatment outcome (GTO) and their satisfaction with care. Cervical lordosis and segmental height were assessed radiographically preoperatively, immediately postoperatively, and at the last follow-up (LFU) (18.2 \pm 13.3 months). RESULTS One hundred and forty-four consecutive patients (113 with APF) were included. The use of APF versus stand-alone methods was associated with significantly increased segmental height (by $2.6 \pm 2.6$ versus $1.5 \pm 2.4 \mathrm{~mm}, \mathrm{p}=0.04$ ) and preservation of lordosis (by $2.7 \pm 4.4^{\circ}$ versus $-1.7 \pm$ $5^{\circ}, \mathrm{p}<0.0001$ ) at LFU, with comparable clinical outcome (COMI score reduction 3.1-point). Multiple regression controlling for potential confounders revealed that APF $(\mathrm{p}=0.0004)$ and cage $(\mathrm{p}=0.001)$ were associated with greater segmental height at LFU; APF was associated with a greater lordosis angle at LFU ( $p<0.0001)$. Greater increase in segmental height at LFU $(p=0.02)$ was associated with a better GTO. CONCLUSIONS Adding APF was associated with greater segmental height and preservation of lordosis in two-level ACDF, especially using bone autograft, but also for cage. Clinical outcome was comparable for all groups. Though the surgical technique per se did not determine clinical outcome, patients achieving a greater segmental height difference showed a significantly better GTO.
\end{abstract}

DOI: https://doi.org/10.1007/s00586-014-3456-y

Posted at the Zurich Open Repository and Archive, University of Zurich

ZORA URL: https://doi.org/10.5167/uzh-109298

Journal Article

Accepted Version

Originally published at:

Burkhardt, Jan-Karl; Mannion, Anne F; Marbacher, Serge; Kleinstück, Frank S; Jeszenszky, Dezsö; Porchet, François (2015). The influence of cervical plate fixation with either autologous bone or cage insertion on radiographic and patient-rated outcomes after two-level anterior cervical discectomy and fusion. European Spine Journal, 24(1):113-119.

DOI: https://doi.org/10.1007/s00586-014-3456-y 
The influence of cervical plate fixation with either autologous bone or cage insertion on radiographic and patient-rated outcomes after two-level anterior cervical discectomy and fusion

Jan-Karl Burkhardt, M.D., ${ }^{1, \#}$ Anne F. Mannion, Ph.D., ${ }^{2}$ Serge Marbacher, M.D., ${ }^{1}$ Frank S. Kleinstück, M.D., ${ }^{3}$ Dezsö Jeszenszky, M.D. ${ }^{3}$ and François Porchet, M.D. ${ }^{1}$

${ }^{1}$ Department of Neurosurgery, ${ }^{2}$ Department of Research and Development, ${ }^{3}$ Department of Orthopedic Surgery, Spine Center, Schulthess Clinic, Zurich, Switzerland

${ }^{\#}$ Corresponding author

Address of correspondence:

Jan-Karl Burkhardt, MD

Spine Center, Department of Neurosurgery

Schulthess Clinic

Lengghalde 2

8008 Zurich, Switzerland

Tel.: $+41 / 443857171$

Fax.: $+41 / 443857171$

E-Mail: JanKarl.Burkhardt@gmail.com

\section{Keywords:}

Two-level anterior cervical discectomy fusion (ACDF), anterior cervical plate, stand-alone, patient-rated outcome. 


\section{Abstract}

Purpose We aimed to identify technique-related factors influencing radiographic and patientrated outcomes after two-level anterior cervical discectomy with fusion (ACDF) using either cage or autologous bone, with or without anterior plate fixation (APF).

Methods This single center study was nested within the Eurospine Spine Tango data acquisition system. Inclusion criteria: consecutive two-level ACDF patients (2004-2012) presenting with signs of degenerative cervical radiculopathy or myelopathy. Before and 12 month postoperatively, patients completed the multidimensional Core Outcome Measures Index (COMI), rated the Global Treatment Outcome (GTO) and satisfaction with care. Cervical lordosis and segmental height were assessed radiographically before, immediately postoperatively, and at last follow-up (18.2 \pm 13.3 months).

Results 144 consecutive patients (112 with APF) were included. The use of APF versus stand-alone methods was associated with significantly increased segmental height $(2.6 \pm 2.6 \mathrm{~mm}$ vs. $1.5 \pm 2.3 \mathrm{~mm}, \mathrm{p}=0.03)$ and preservation of lordosis $\left(2.8^{\circ}\right.$ vs. $\left.-1.7^{\circ}, \mathrm{p}<0.0001\right)$ at LFU, with comparable clinical outcome (COMI score reduction $\geq 3$.3-point). Multiple regression controlling for potential confounders revealed that APF $(p=0.0008)$ and cage $(p=0.004)$ were associated with greater segmental height at LFU; APF was associated with a greater lordosis angle at LFU $(\mathrm{p}<0.0001)$. Greater increase in segmental height at LFU $(p=0.02)$ was associated with a better GTO.

Conclusions Adding APF was associated with greater segmental height and preservation of lordosis in two-level ACDF, especially using bone autograft, but also for cage. Clinical outcome was comparable for all groups. Though the surgical technique per se did not determine clinical outcome, patients achieving a greater segmental height difference showed a significantly better GTO. 


\section{Introduction}

Anterior cervical discectomy with fusion (ACDF) is a standard surgical technique to treat degenerative cervical radiculopathy or myelopathy (DCRM) via an anterior approach.[1,2] Since its first description by Smith and Robinson many different modifications of this technique have been reported.[3,4] After removal of the intervertebral disc, either autologous bone or a cage - with or without anterior plate fixation (APF) - are current options for fusion.[5-7]

For single-level ACDF the use of a cage or autologous bone, with or without APF, has shown comparable clinical and radiographic results, with a tendency for better radiographic outcome in patients with APF.[8,9] However, for more than 1-level ACDF there is currently no evidence in the literature suggesting superiority of one technique over any other, especially regarding the issue of whether APF is superior to the stand-alone technique.[10,11] Some smaller studies report an advantage of APF in terms of radiographic outcome, but there is no systematic study in the literature analyzing the influence of APF in terms of both patient-rated and radiographic outcomes in two-level ACDF. Therefore, we aimed to identify techniquerelated factors after two-level ACDF to evaluate whether the addition of an anterior cervical plate shows superiority over a stand-alone technique in terms of radiographic and patientrated outcome.

\section{Material and Methods}

\section{Patient data and inclusion criteria}

This was a single center study nested within the Eurospine Spine Tango data acquisition system. It comprised a retrospective analysis of prospectively collected data. Cases were identified using the Spine Tango system and our local Outcomes database and were verified by cross-checking with the information in our local Clinic Information System. Inclusion criteria were: consecutive patients between 2004 - 2012 presenting with signs of DCRM 
undergoing $\mathrm{ACDF}$ at two levels due to degenerative stenosis; German or English speaking patients (or in more recent years (after 2007), also Spanish, Italian, French, or Portuguese speaking). Exclusion criteria were: ACDF performed at non-consecutive levels (floating fusion); prior cervical fusion surgery; additional posterior instrumented fusion at the same levels; incomplete radiographic data either pre-/postoperative or at last follow-up (LFU) (20 patients with APF and 1 patient without APF were excluded from this study) Limitations of this study include its retrospective nature and the lack of randomization. Surgical decisionmaking and use of surgical technique was at the discretion of the treating surgeon.

\section{Surgical technique}

ACDF techniques were performed as previously described via a standard cervical anterior approach.[12,5] After discectomy, either an iliac bone graft or a cage (PEEK cages, Medtronic or DePuy), with or without plate (Zephir, Medtronic or Skyline, DePuy), was used for fusion to restore the height as much as possible.

\section{Data acquisition system and patient-orientated questionnaires}

Using the prospective Eurospine Spine Tango data acquisition system[13] all relevant patient data was documented by the physician during the hospital stay including pathology, previous treatment, patient comorbidity status assessed with the American Society of Anesthesiologists Physical Status Score (ASA score), surgical procedure, number of affected levels, duration of surgery (in categories, from $<1 \mathrm{~h}$ to $>10 \mathrm{~h}$ ), blood loss (in categories from none to $>2,000 \mathrm{ml}$ ), and both general and surgical complications.

Patients completed the multidimensional Core Outcome Measures Index (COMI) questionnaire before and 12 months after surgery.[14] The questionnaire was sent to the patients by post, to be completed at home. The COMI (scored 0-10) consists of questions covering the domains of pain, function, symptom specific well-being, general quality of life, 
and social and work disability.[14,15] In addition, Global Treatment Outcome (GTO) at 12 months follow-up was assessed with a question enquiring as to how much the operation had helped the neck problem, overall (with five response categories from "helped a lot" to “'made things worse'), Patient-rated satisfaction with care was also rated using a 5-point Likert scale ("over the course of treatment for your neck problem how satisfied were you with the medical care in our hospital?"; response categories from "very satisfied" to "very dissatisfied"').

\section{Radiographic measurements}

Radiographic measurements included segmental height and cervical lordosis, which were measured on plain lateral radiographs with the patient in the neutral position. Measurements were made before and within the first week after surgery, and at the last follow-up as described previously.[16] To assess segmental height the distance between the midpoint of the involved cranial and caudal vertebral bodies was measured. Cervical lordosis was defined as the angle between the lower end-plate of $\mathrm{C} 2$ and the upper endplate of $\mathrm{C} 7$ using Cobb's method. Fusion rate was not assessed, since CT scans or functional x-ray were not available after surgery for most of the patients.

\section{Statistical analyses}

Descriptive data are presented as mean \pm standard deviations (SD). The significance of differences between the APF and stand-alone ACDF groups for continuous, normally distributed data was analyzed using unpaired Student's t-tests or (for pre/post measures) repeated measures analysis of variance. Contingency analyses with Chi-squared or the Fishers exact test was used to analyze the association between surgical group and categorical variables. The global outcome was dichotomized into "good" (=operation helped or helped a lot) and "poor" (=operation only helped a little, did not help, made things worse) for some 
analyses. A two-way analysis of variance (two between factors: APF vs stand-alone; cage vs bone) was used to examine the difference between groups for the radiographic measures. Multiple linear regression analysis was used to evaluate the influence of surgical technique (APF versus stand-alone, cage versus bone) on radiographic outcome, and of radiographic measures (segmental height, lordosis) on clinical outcome, in each case whilst controlling for potential confounding variables (age, gender, comorbidity, and preoperative values for the dependent variable in question). Statistical significance was accepted at the $\mathrm{P}<0.05$ level.

\section{Results}

Overall study group

144 consecutive patients with two-level ACDF were identified for analysis. This included 112 patients with APF (90 with autologous bone and 20 with cage), and 32 with no APF (10 with stand-alone autologous bone and 22 with stand-alone cage). C5-7 were the segments most commonly operated (77/144 (53\%)), followed by C4-6 (53/144 (37\%)), C3-5 (13/144 (9\%)) and C6-T1 (1/144 (1\%)).

\section{Anterior plate fixation versus stand-alone 2-level ACDF}

There was no statistically significant difference $(p>0.05)$ between patients who had received APF and those in whom a stand-alone technique had been used in terms of their age, gender or baseline self-reported symptoms, function, quality of life, etc. (COMI domains); however, there was a tendency $(p=0.056)$ for greater comorbidity in the group without anterior plate fixation (Table 1). Duration of surgery differed significantly $(\mathrm{p}=0.001)$ between the two groups, with shorter surgery time in the stand-alone patient group. Blood loss during surgery and both surgical and general (medical) perioperative complication rates were comparable between the two groups with a slightly, but not significantly higher complication rate in the stand-alone group (Table 2). 
There was no significant difference between the groups (APF versus stand-alone) for the absolute values of segmental height and lordosis angle at baseline, directly postoperative and LFU (group difference in each case, $\mathrm{p}>0.05$; Table 3 ). However, there was significant subsidence and loss of lordosis over time in both groups, with a significantly greater effect in the group without anterior plate fixation (Table 3).

There was no significant difference between the groups for any of the patient-rated outcomes at 12 months (Table 4). A good global outcome (operation helped/helped a lot) was reported by $78 \%$ patients in the APF group and $87 \%$ patients in stand-alone group $(p=0.28)$. A total of $88 \%$ patients in the APF group were satisfied/very satisfied with their care compared with $90 \%$ in the stand-alone group $(\mathrm{p}=0.77)$. In each group there was a statistically significant $(\mathrm{p}<0.0001)$ and clinically relevant reduction (of $\geq 3.3$-point) in the multidimensional COMI score 12 months after surgery, with no significant difference $(p=0.69)$ between the groups (Table 4).

\section{Determinants of radiographic and clinical outcome after 2-level ACDF}

Two-way analysis of variance revealed that there was a significant main effect of fusion type/material on the change in segmental height from preoperative to LFU, with cage being superior to bone $(\mathrm{p}=0.023)$; similarly, the use of APF was superior to the stand-alone technique $(\mathrm{p}=0.005)$. There was also a significant interaction between these factors indicating that the influence of adding a plate was much more marked in the group with autologous bone than in those with a cage $(\mathrm{p}=0.036)$ (Figure 1). With regards to the change in lordosis angle from preoperative to LFU, there was a significant main effect in relation to the use of a plate (better maintenance of lordosis with APF than with stand-alone technique; $p<0.0001$ ) and a tendency for the addition of a plate to have a more marked effect in the group with autologous bone than in the cage group $(\mathrm{p}=0.13)$. Multiple regression analysis controlling for possible confounders (see methods) confirmed these findings and showed that the use of APF rather 
than stand-alone methods $(\mathrm{p}=0.0008)$ and a cage rather than bone $(\mathrm{p}=0.004)$ were both unique statistical predictors of a greater segmental height at LFU (Table 5); the use of APF was a significant predictor of a greater lordosis angle at LFU $(\mathrm{p}<0.0001)$.

Multiple regression analyses controlling for confounders revealed that, though the surgical technique per se did not determine clinical outcome, a greater change in segmental height (but not lordosis angle) preoperatively to LFU was associated with a better GTO $(p=0.02)$; the same analysis using the COMI score as the dependent variable revealed only a non-significant trend $(\mathrm{p}=0.26)$.

\section{Discussion}

There is ongoing discussion in the literature regarding the optimal surgical technique in twolevel ACDF. In the present study, we analyzed the factors related to the surgical technique that influenced radiographic and patient-rated outcome.

Previously published studies including single and multilevel ACDF have reported that using a cage with APF results in a comparable clinical outcome to that of stand-alone techniques, but with a better lordotic alignment, increased disk height and lower subsidence.[17,11] A recently published prospective study, in which single level ACDF using either autologous bone fusion with APF or stand-alone cage fusion, reported improved radiological outcomes after APF but comparable clinical outcomes for both techniques.[8] However, Joo et al. reported no significant differences in radiographic or clinical outcomes between stand alone cage fusion and fusion with cage plus APF.[10]

We present one of the largest series in the literature analyzing differences in radiographic and clinical outcome after two-level ACDF using cage or autologous bone, with or without APF. Our results show that these four surgical techniques are safe and effective in the treatment of cervical spondylotic myelopathy and result in similarly good patient-orientated outcomes, but 
with a significantly greater segmental height and preservation of lordosis in patients with APF.

\section{Anterior plate fixation versus stand-alone 2-level ACDF}

Age, gender, baseline self-reported symptoms, function and quality of life were comparable in the groups with and without APF, with a tendency for greater comorbidity in the group without APF. There was a significantly longer surgery time in the APF group, explainable by the additional time required to add a plate after cage/bone fusion. Perioperative complications were slightly, but not significantly higher in the stand-alone group. This was most likely related to the higher comorbidity status of these patients. Due to the retrospective nature of the study, it remains unclear whether the surgical strategy of a stand-alone technique was selected in patients with greater comorbidity in order to reduce surgery time and potential perioperative complications.

The radiographic outcome was significantly different between the groups (with and without APF) with a greater segmental height and preservation of lordosis in the APF group. In both groups a subsidence effect and loss of lordosis was measured, with a significantly greater effect in the group without APF. These results are consistent with those from other studies[17,11]. The greater preservation of segmental height and lordosis in the APF group might be due to stabilization of the operated segments within the first weeks after surgery while the autologous fusion was progressing.[9] Interestingly, however, there was no significant difference between the two groups in terms of their clinical outcome. At the final follow-up, both groups showed a statistically significant and clinically relevant improvement upon their preoperative status. Wu et al. reported similar good clinical outcomes although in their study, cervical lordosis improvement was related to better clinical outcome.[18] No such correlation was found in our study. 


\section{Determinants of radiographic and clinical outcome after 2-level ACDF}

Similar to previously published studies[19] our data showed that the use of a cage was superior to autologous bone in terms of restoration and preservation of disc height; also in accordance with the literature[11], we showed that APF was superior to a stand-alone technique. The effect of adding a plate was significantly more marked in the autologous bone group than in the cage group showing the importance of adding APF in this subgroup to guarantee preservation of disc height. Analogous to the findings for segmental height, improvement in the lordosis angle was also significantly related to the use of APF and with a tendency for APF to have a more marked effect in the group with autologous bone than in the cage group. These findings are in accordance with the conclusions of previously published studies.[19,20]

Although we found no significant effect of surgical technique per se on clinical outcome, a greater change in segmental height preoperatively to LFU was associated with a significantly better GTO and a trend for a greater reduction (i.e. improvement) in the COMI score. The finding of a better clinical outcome when disc height is preserved might be explained by a larger space in the foramen being made available for the corresponding nerves.

Limitations of our study include its retrospective nature (although the patient outcome data were collected prospectively) and the lack of randomization of the patients to either cage or autologous bone with/without APF groups. Instead, surgical decision-making and use of surgical technique was at the discretion of the treating surgeon and also different implants and technique may have influenced the results. Nonetheless, on the basis of patient-rated outcome measures, collected with a very high follow-up rate of $>94 \%$, the study showed that all four techniques resulted in a high proportion of patients reporting a good global outcome and satisfaction with care. The similarity in clinical outcome for the two groups precludes any conclusions regarding the superiority of one technique over the other, though the significantly better GTO in patients with greater segmental height after surgery suggests that preservation 
and/or improvement of the sagittal alignment and balance of the cervical spine may be important. Based on these results showing that APF results in a better radiographic profile, we tentatively conclude that APF rather than stand-alone techniques should be the preferred option in 2-level ACDF. However, this would need to be confirmed by means of a prospective randomized trial.

\section{Disclosure}

The authors report no conflict of interest concerning the materials or methods used in this study or the findings specified in this paper. 


\section{References}

1. Cunningham MR, Hershman S, Bendo J (2010) Systematic review of cohort studies comparing surgical treatments for cervical spondylotic myelopathy. Spine (Phila Pa 1976) 35 (5):537-543. doi:10.1097/BRS.0b013e3181b204cc

00007632-201003010-00012 [pii]

2. Matz PG, Ryken TC, Groff MW, Vresilovic EJ, Anderson PA, Heary RF, Holly LT, Kaiser MG, Mummaneni PV, Choudhri TF, Resnick DK, Joint Section on Disorders of the S, Peripheral Nerves of the American Association of Neurological S, Congress of Neurological S (2009) Techniques for anterior cervical decompression for radiculopathy. J Neurosurg Spine 11 (2):183-197. doi:10.3171/2009.2.SPINE08721

3. Smith GW, Robinson RA (1958) The treatment of certain cervical-spine disorders by anterior removal of the intervertebral disc and interbody fusion. J Bone Joint Surg Am 40-A (3):607-624

4. Jacobs W, Willems PC, Kruyt M, van Limbeek J, Anderson PG, Pavlov P, Bartels R, Oner C (2011) Systematic review of anterior interbody fusion techniques for single- and doublelevel cervical degenerative disc disease. Spine (Phila Pa 1976) 36 (14):E950-960. doi:10.1097/BRS.0b013e31821cbba5

5. Rao RD, Gourab K, David KS (2006) Operative treatment of cervical spondylotic myelopathy. J Bone Joint Surg Am 88 (7):1619-1640. doi:88/7/1619 [pii] 10.2106/JBJS.F.00014

6. Chen Y, Wang X, Lu X, Yang L, Yang H, Yuan W, Chen D (2013) Comparison of titanium and polyetheretherketone (PEEK) cages in the surgical treatment of multilevel cervical spondylotic myelopathy: a prospective, randomized, control study with over 7-year follow-up. Eur Spine J 22 (7):1539-1546. doi:10.1007/s00586-013-2772-y 
7. Guo Q, Bi X, Ni B, Lu X, Chen J, Yang J, Yu Y (2011) Outcomes of three anterior decompression and fusion techniques in the treatment of three-level cervical spondylosis. Eur Spine J 20 (9):1539-1544. doi:10.1007/s00586-011-1735-4

8. Kim CH, Chung CK, Hahn S (2013) Autologous iliac bone graft with anterior plating is advantageous over the stand-alone cage for segmental lordosis in single-level cervical disc disease. Neurosurgery 72 (2):257-265; discussion 266. doi:10.1227/NEU.0b013e31827b94d4

9. Daffner SD, Wang JC (2009) Anterior cervical fusion: the role of anterior plating. Instr Course Lect 58:689-698

10. Joo YH, Lee JW, Kwon KY, Rhee JJ, Lee HK (2010) Comparison of fusion with cage alone and plate instrumentation in two-level cervical degenerative disease. J Korean Neurosurg Soc 48 (4):342-346. doi:10.3340/jkns.2010.48.4.342

11. Oh JK, Kim TY, Lee HS, You NK, Choi GH, Yi S, Ha Y, Kim KN, Yoon DH, Shin HC (2012) Stand-alone Cervical Cages Versus Anterior Cervical Plate in 2-Level Cervical Anterior Interbody Fusion Patients: Clinical Outcomes and Radiologic Changes. J Spinal Disord Tech. doi:10.1097/BSD.0b013e31824c7d22

12. Grob D, Porchet F, Kleinstuck FS, Lattig F, Jeszenszky D, Luca A, Mutter U, Mannion AF (2010) A comparison of outcomes of cervical disc arthroplasty and fusion in everyday clinical practice: surgical and methodological aspects. Eur Spine J 19 (2):297-306. doi:10.1007/s00586-009-1194-3

13. Roder C, Chavanne A, Mannion AF, Grob D, Aebi M (2005) SSE Spine Tango--content, workflow, set-up. http://www.eurospine.org-Spine Tango. Eur Spine J 14 (10):920-924. doi:10.1007/s00586-005-1023-2

14. Mannion AF, Elfering A, Staerkle R, Junge A, Grob D, Semmer NK, Jacobshagen N, Dvorak J, Boos N (2005) Outcome assessment in low back pain: how low can you go? Eur Spine J 14 (10):1014-1026. doi:10.1007/s00586-005-0911-9 
15. Mannion AF, Porchet F, Kleinstuck FS, Lattig F, Jeszenszky D, Bartanusz V, Dvorak J, Grob D (2009) The quality of spine surgery from the patient's perspective. Part 1: the Core Outcome Measures Index in clinical practice. Eur Spine J 18 Suppl 3:367-373. doi:10.1007/s00586-009-0942-8

16. Burkhardt JK, Mannion AF, Marbacher S, Dolp PA, Fekete TF, Jeszenszky D, Porchet F (2013) A comparative effectiveness study of patient-rated and radiographic outcome after 2 types of decompression with fusion for spondylotic myelopathy: anterior cervical discectomy versus corpectomy. Neurosurg Focus 35 (1):E4. doi:10.3171/2013.3.FOCUS1396

17. Song KJ, Taghavi CE, Lee KB, Song JH, Eun JP (2009) The efficacy of plate construct augmentation versus cage alone in anterior cervical fusion. Spine (Phila $\mathrm{Pa}$ 1976) 34 (26):2886-2892. doi:10.1097/BRS.0b013e3181b64f2c

18. Wu WJ, Jiang LS, Liang Y, Dai LY (2012) Cage subsidence does not, but cervical lordosis improvement does affect the long-term results of anterior cervical fusion with standalone cage for degenerative cervical disc disease: a retrospective study. Eur Spine J 21 (7):1374-1382. doi:10.1007/s00586-011-2131-9

19. Liebensteiner MC, Jesacher G, Thaler M, Gstoettner M, Liebensteiner MV, Bach CM (2011) Restoration and preservation of disc height and segmental lordosis with circumferential lumbar fusion: a retrospective analysis of cage versus bone graft. J Spinal Disord Tech 24 (1):44-49. doi:10.1097/BSD.0b013e3181d67c7c

00024720-201102000-00009 [pii]

20. Kim MK, Kim SM, Jeon KM, Kim TS (2012) Radiographic Comparison of Four Anterior Fusion Methods in Two Level Cervical Disc Diseases : Autograft Plate Fixation versus Cage Plate Fixation versus Stand-Alone Cage Fusion versus Corpectomy and Plate Fixation. J Korean Neurosurg Soc 51 (3):135-140. doi:10.3340/jkns.2012.51.3.135 


\section{Figure Legend}

Figure 1: Segmental height differences preoperatively to last follow-up (LFU) for patients with autologous bone or cage, with either anterior plate fixation (APF) or stand-alone. Values are means with standard errors.

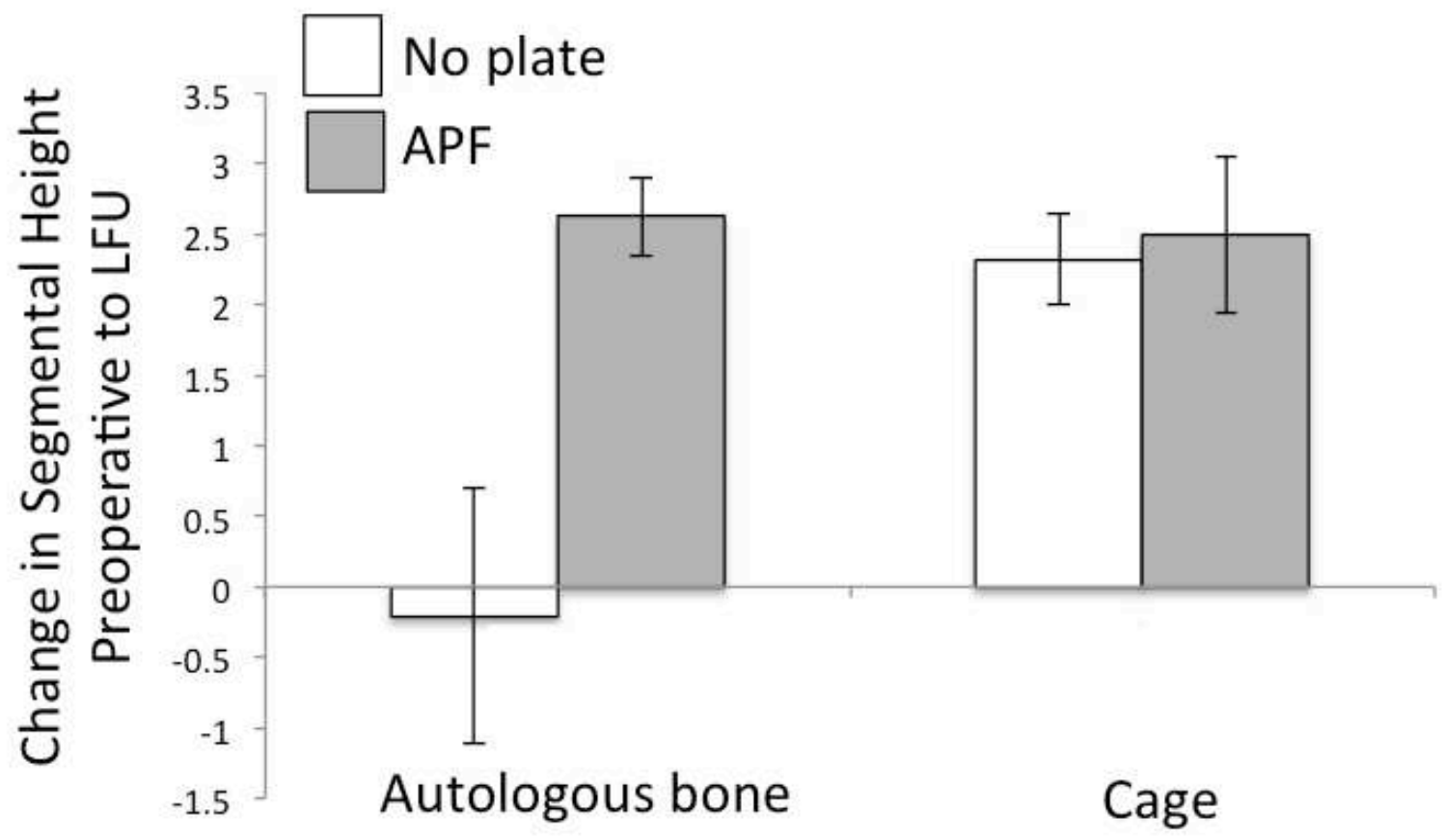

